In conclusion, the blockage of insulin secretion from the pancreas, which has recently been demonstrated in vitro $^{5}$, also occurs in vivo. The block appears to be directed specifically to the glucose-sensitive receptor, the stimulation of which results in insulin secretion into the blood.

We thank Prof. M. C. Shelesnyak for his advice. This work was supported in part by U.S. Public Health Service research grant $A M$ 05701-02 $M E T$ from the National Institute of Arthritis and Metabolic Diseases, Bethesda, Maryland.

\section{ERnst Simon}

Peretz F. Kratcer

Biodynamies Institute,

Weizmann Institute of Science, Rohovoth, Israel.

${ }^{1}$ Simon, E., and Kraicer, P. F., Arch. Biochem. Biophys., 69, $592(1957)$.

${ }^{2}$ Simon, E., Kraicer, P. F., and Shelesnyak, M. C., Endocrinol., r1, 83 (1962). ' Kraicer, P. F., and Simon, E., Acta Endocrinol., 47, 517 (1964).

'Simon, E., and Kraicer, P. F., presented at the Fifth Congr. Intern. Diabetes Federation, Toronto, July 20-24, 1964. Coore, H. G., and Randle, P. J. Biochem. J., 93, 66 (1964).

Coore, H. G., Randle, P. J., Simon, E., Kraicer, P. F., and Shelesnyak, M. C., Nature, $19^{72}, 1^{1264}(1963)$

\section{Resorption of Metallic Mercury by the Conjunctiva}

THE aim of this work has been to determine $(a)$ whether metallic mercury, locally applied to the conjunctival sac, can be resorbed there in such a degree that its presence can be detected in urine, and $(b)$ the nature of the local reaction of the epithelial cover to a direct contact with metallic mercury.

Experiments were carried out on 12 rabbits. Metallic mercury was applied into the conjunctival sac of one eye, the second eye being the control. Mercury in various amounts $(1.0 \mathrm{~g}, 1.5 \mathrm{~g}, 2.0 \mathrm{~g}$ or $2.5 \mathrm{~g})$ was applied for various periods ( $30 \mathrm{~min}, 24 \mathrm{~h}$ or $48 \mathrm{~h}$ ) once or several times. To avoid resorption of mercury by the respiratory tract a small mask was placed over the oral cavity. The eye was bandaged after the application of mercury or, if the mercury was to remain for $24 \mathrm{~h}$ or $48 \mathrm{~h}$, the eyelids were sutured (tarsorraphy).

Urine was tested for mercury 5 days before the initiation of the experiments, and during and up to the 16th day after the last application of mercury.

All the experimental animals excreted mercury in the urine, although there was no correlation whatever between the amount of mercury applied and the amount excreted in the urine. The amount excreted varied very widely, from $20 \gamma$ to $600 \gamma$ at a time. The total amount of mercury excreted ranged from $40 \gamma$ to $870 \gamma$ for a single animal. Similarly, the rate of excretion of mercury showed no regular relation with time of administration. Not more than 9 per cent $\left(r^{2} x y\right)$ of the variation in the amount of mercury eliminated in the urine is accounted for by the variation in the resorption index.

During local reaction of the conjunctiva after application of metallic mercury into the conjunctival sac, there were no clinical symptoms of irritation in the conjunctiva, but in conjunctival smears a cytological reaction in the form of an increased number of lymphocytes and lymphocytelike cells, macrophages and an increased amount of altered mucus were observed. It has been possible to demonstrate histochemically (by a modified Feigl's ${ }^{1}$ method) the presence of mercury in exfoliated epithelia of the conjunctiva, in migrating macrophages, and in conjunctival mucus.

\section{B. KULCZYCKA}

Jepartment of Animal Physiology, Jagiellonian University, Kraków, Poland.

${ }^{1}$ Feigl, F., Spot Tests (Elsevier Publ. Company, 1958).

\section{Small Bowel Tonometry : Assessment of Small Gut Mucosal Oxygen Tension in Dog and Man}

VARIOUS methods have been used to assess tissue oxygen tension $^{1-3}$ and recently the gall bladder and urinary bladder have been used as hollow viscus tonometers ${ }^{4}$. We have applied this principle in an attempt to measure the oxygen tension of the small gut mucosa of dog and man. Six dogs were anaesthetized with 'Nembutal', intubated and arterial $p \mathrm{CO}_{2}$ maintained between 35 and $45 \mathrm{~mm}$ mercury by using a respirator; arterial $p \mathrm{O}_{2}$ was kept. between 95 and $110 \mathrm{~mm}$ mercury by enriching the inspired air with oxygen. Loops of jejunum $(23 \mathrm{~cm})$ and ileum $(29 \mathrm{~cm})$ were prepared so that their contents could be sampled through an indwelling polyvinyl tube after they had been returned to the abdomen and the abdomen had been closed ${ }^{5}$. The temperature of the animals was maintained between $37^{\circ}$ and $39.5^{\circ}$ C. Nitrogen was bubbled through isotonic sodium chloride at $37^{\circ} \mathrm{C}$; after deoxygenation was complete $40 \mathrm{ml}$. were instilled into each small bowel loop. Samples were removed at various times for the estimation of $p \mathrm{O}_{2}$ and $p \mathrm{CO}_{2}$ with a Severinghaus electrode assembly ${ }^{6}$ and $p \mathrm{H}$ with an Astrup micro-electrode.

The oxygen tension in the luminal saline rapidly increased and reached a plateau (Fig. 1) so that 3 - and 5-min samples were identical. The estimated mucosal $p \mathrm{O}_{2}$ in 6 dogs ranged between 30 and $45 \mathrm{~mm}$ mercury. The results from the ileal loops were similar. One normal volunteer was also intubated and a segment of jejunal blocked off with two balloons? ${ }^{7}$. Deoxygenated saline introduced into this segment reached a stable oxygen tension within 5 min, giving a 'mucosal' $p \mathrm{O}_{2}$ of $45 \mathrm{~mm}$ mercury. The presence of oxygen in the luminal saline was thought not to be an artefact of the sampling technique. In two dogs a $p \mathrm{O}_{2}$ of less than $5 \mathrm{~mm}$ mercury was observed in the contents within $5 \mathrm{~min}$ of clamping the thoracic aorta. Similarly, when the arterial $p_{2}$ was
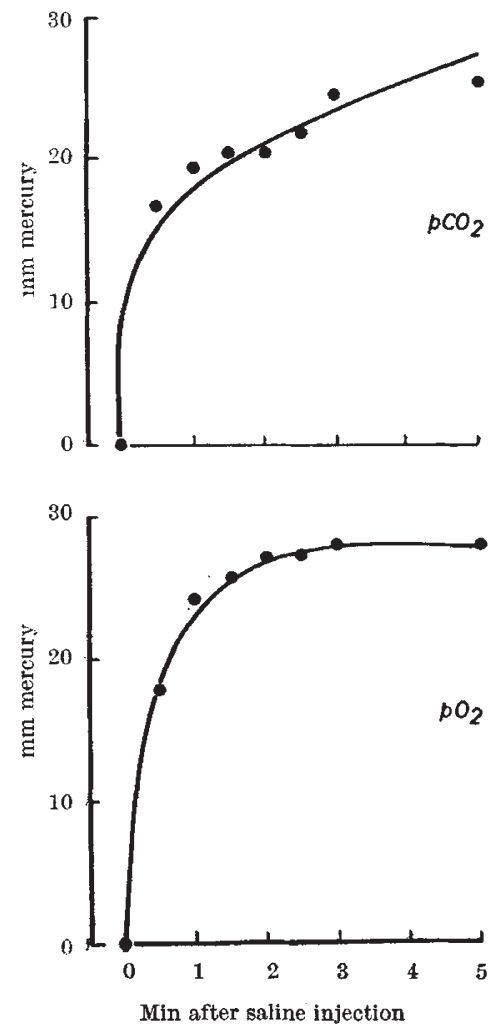

Fig. 1. Luminal gas tension after injection of deoxygenated saline into jejunum of a dog. $\mathrm{PaO}_{2}=110 \mathrm{~mm}-$ mereury $; \mathrm{PaCO}_{2}=35.5 \mathrm{~mm}$ mercury 